\title{
Wettability of Low Silver Content Lead-Free Solder Alloy
}

\author{
I Gusti Bagus Budi Dharma ${ }^{1}$, Mohd Hamdi Abd Shukor ${ }^{1}$ and Tadashi Ariga ${ }^{2}$ \\ ${ }^{1}$ Department of Engineering Design and Manufacture, University of Malaya, Malaysia \\ ${ }^{2}$ Department of Material Science, School of Engineering, Tokai University, Hiratsuka 259-1292, Japan
}

\begin{abstract}
Wettability of low silver $(\mathrm{Ag})$ content $\mathrm{Sn}-x \mathrm{Ag}-0.7 \mathrm{Cu}-0.5 \mathrm{In}$ lead-free solder $(x=0.1,0.3,0.5)$ on copper substrate was investigated. Wetting balance test results indicated that varying small Ag content in the alloy affects the wettability of solders with higher Ag content showing better wettability. The contact angles of the solder alloy showed dependence on Ag content in solder and temperature. Solder alloy with no Ag content and 0.5 mass $\%$ Ag content displayed similar contact angle and qualitatively similar surface tension; however, the maximum wetting force is significantly difference, which indicates difference in the density of solder alloy. Effects of different fluxes on wettability were also studied. [doi:10.2320/matertrans.M2009024]
\end{abstract}

(Received January 19, 2009; Accepted February 23, 2009; Published April 25, 2009)

Keywords: low silver content, wettability, lead-free solder

\section{Introduction}

Tin-Lead $(\mathrm{Sn}-\mathrm{Pb})$ solder alloys have been used since many years in the assembly of modern electronic devices. However, because of the toxicity of Lead to environment and human health, it has stimulated substantial research to discover a replacement, a lead-free solder alloy. Among the numerous lead-free solders, Tin-Copper $(\mathrm{Sn}-\mathrm{Cu})$ based solder alloy is one of the most promising lead-free solder, especially for the wave soldering in electronic packaging. ${ }^{1)}$ The $\mathrm{Sn}-\mathrm{Cu}$ binary alloy has a eutectic composition of Sn-0.7 mass\% which is cheaper than most other candidate alloys. However, tensile and shear-tensile strengths of $\mathrm{Sn}-\mathrm{Cu}$ eutectic solder are lower than $\mathrm{Sn}-\mathrm{Ag}$ and $\mathrm{Sn}-\mathrm{Ag}-\mathrm{Cu}$ eutectic solder. ${ }^{2,3)}$ With a melting point of $500 \mathrm{~K}, \mathrm{Sn}-0.7$ mass $\%$ eutectic can be considered as an alloy with high soldering temperature.

It is known that the microstructure of eutectic $\mathrm{Sn}-0.7 \mathrm{Cu}$ can be altered by the addition of small quantities of certain alloying elements to improve its mechanical properties. ${ }^{4)}$ In this study, Silver (Ag) and Indium (In) were added to Sn$0.7 \mathrm{Cu}$ eutectic alloy to improve its wettability and mechanical properties.

$\mathrm{Ag}$ an essential component in $\mathrm{Pb}$-free solders which can enhance wetting characteristic and joint strength. ${ }^{5)}$ However, nowadays, the price of silver becomes a major manufacturing issue. ${ }^{6}$ Little variations in the amount of silver can significantly affect the mechanical properties of that alloy since the concentration of those elements in a solder matrix is relatively small.7) Indium content in solders can reduce its melting temperature. ${ }^{8,9)}$ In this study, wettability of Sn- $x \mathrm{Ag}$ $0.7 \mathrm{Cu}-0.5 \mathrm{In}$ solder alloy were investigated by varying the quantity of $\mathrm{Ag}(x=0.1-0.5)$.

\section{Theory}

Wetting balance analysis measures the wetting forces imposed by the molten solder on the test surface as it is dipped into and held in the solder bath as a function of time and plotted. Figure 1 shows a typical wetting balance curve. In this force-time curve, there are two most common values used as the wettability parameters: the wetting time $\left(\mathrm{t}_{1}\right)$ and the maximum wetting force $\left(F_{\max }\right) .^{10,11)}$ The time at which the solder contact angle to the specimen is $90^{\circ}$, or for the measured wetting force to return to zero are widely used as the wetting time. ${ }^{12)}$ The maximum wetting force is obtained when the meniscus is stabilized after immersion and the measured force remained constant. The wetting force, $F$, in the static equilibrium condition can be expressed as follows: ${ }^{10)}$

$$
F=\mathrm{p} \gamma \cos \theta-\rho \mathrm{g} V
$$

where $\mathrm{p}$ is the perimeter of the specimen, $\gamma$ is the surface tension of the solder in contact with the flux, $\theta$ is the contact angle, $\rho$ is the density of the solder, $g$ is the gravity acceleration constant and $V$ is an immersed volume.

\section{Experimental Procedures}

The wetting balance test was conducted using a SAT5100 (Rhesca Co., Ltd. Japan). Parameters used for wetting balance test were $5 \mathrm{~mm} \mathrm{~s}^{-1}$ of dipping speed with a dipping depth of $10 \mathrm{~mm}$. The dipping time was $20 \mathrm{~s}$, and the testing temperature was $523 \mathrm{~K}$. Wetting time and wetting force were measured.

Oxygen Free High Conductivity (OFHC) Copper sheet, $10 \mathrm{~mm} \times 30 \mathrm{~mm} \times 0.3 \mathrm{~mm}$ was used as substrate metal. It was sequentially cleaned and degreased in an acetone and 5 vol\% $\mathrm{HCl}$ acid solution.

The spreading test was conducted using a SAT5100 (Rhesca Co., Ltd. Japan) as a heat source. The OFHC copper sheet $30 \mathrm{~mm} \times 30 \mathrm{~mm} \times 0.3 \mathrm{~mm}$ was used as a substrate. The testing temperature was $523 \mathrm{~K}$. Solder alloys were remelted and poured into a mold to make a rod with $5 \mathrm{~mm}$ diameter. The rod was sliced to get $2 \mathrm{~mm}$ thickness solder disc with weight around $0.3 \mathrm{~g}$. The solder was allowed to melt and spread onto substrate for 30 seconds and then the sample was cooled in room temperature.

Contact angles were measured via spreading test specimens. The contact angle of the solder was measured from an image taken by digital camera capturing the cross section profile of spreading specimen with backlight system. Figure 2 shows a schematic diagram of capturing specimen profile. An example image captured from the digital camera is shown in Fig. 3. 


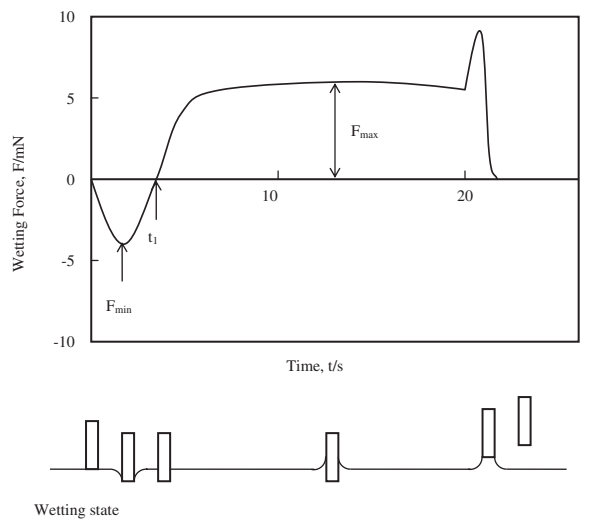

Fig. 1 A typical wetting balance curve and wetting state.

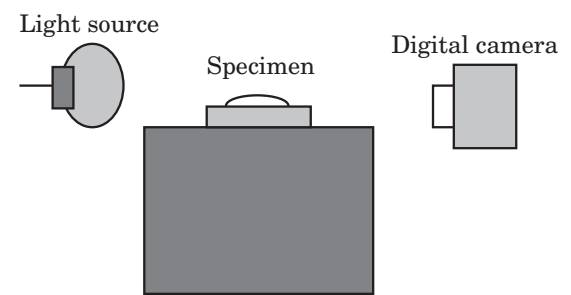

Fig. 2 Schematic diagram of capturing specimen profile.

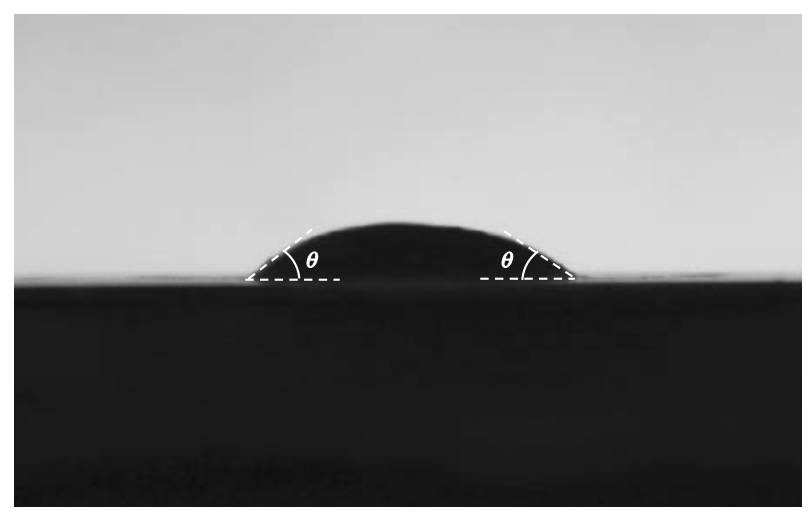

Fig. 3 Image of specimen for contact angle measurement.

The solder alloy were purchased from Nihon Almit Co. Ltd. Japan in a bar form. In this experiment, 2 kinds of flux were used-Rosin Flux and Commercial Rosin Mildly Activated (RMA) Flux. Liquid rosin flux was obtained by mixing solid rosin flux and isopropyl alcohol at a weight ratio of $1: 5$.

\section{Results and Discussions}

\subsection{Wetting balance test}

Wetting balance test results with Rosin flux are shown in Fig. 4 and Fig. 5. All solder alloys generally showed an increase in maximum wetting force $\left(\mathrm{F}_{\max }\right)$ and decrease in wetting time $\left(\mathrm{t}_{1}\right)$ as the temperature is increased. In Fig. $4, \mathrm{t}_{1}$ of the alloys decreased greatly as the temperature increased from 523 to $543 \mathrm{~K}$. However, further increase in temperature to $563 \mathrm{~K}$ did not lead to a significant decrease in $\mathrm{t}_{1}$ as there was small difference between $\mathrm{t}_{1}$ at $543 \mathrm{~K}$ and at $563 \mathrm{~K}$. At

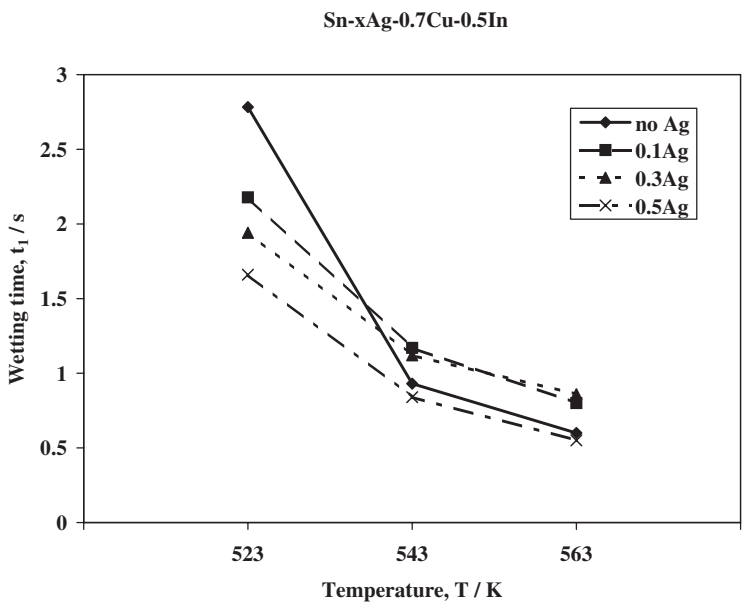

Fig. 4 Wetting time of lead-free solders with Rosin flux.

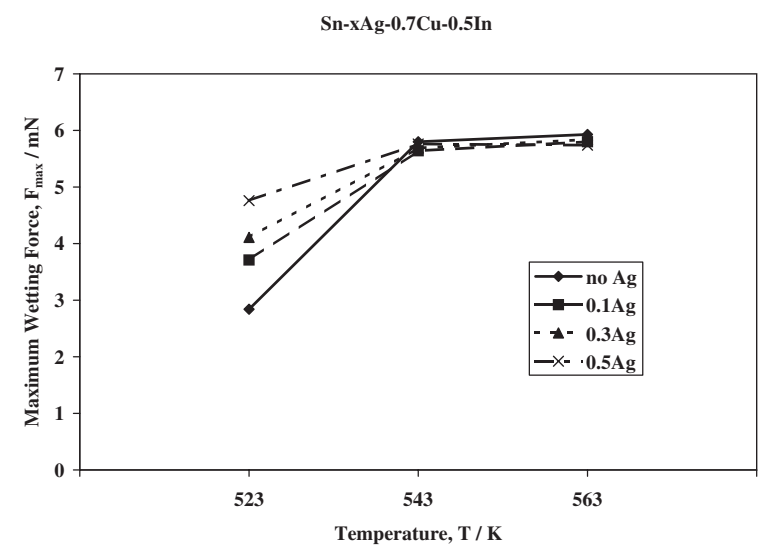

Fig. 5 Maximum wetting force of lead-free solders with Rosin flux.

$523 \mathrm{~K}$, addition $\mathrm{Ag}$ content up to 0.5 mass $\%$ resulted significant decreasing in $\mathrm{t}_{1}$ from 2.78 to $1.66 \mathrm{~s}$ which is $1.12 \mathrm{~s}$ differences. Further increasing temperature to $543 \mathrm{~K}$ and $563 \mathrm{~K}$, the difference became smaller, which are $0.09 \mathrm{~s}$ and $0.05 \mathrm{~s}$ difference respectively. Increasing $\mathrm{Ag}$ content in the solder may lead to decreasing of wetting time of solder. This argument is in agreement where highest $\mathrm{Ag}$ content resulted lowest wetting time at all temperature.

The $\mathrm{F}_{\max }$ of solder alloys are shown in Fig. 5. $\mathrm{F}_{\max }$ tend to increase with increasing temperature. The highest increasing in $\mathrm{F}_{\max }$ obtained when temperature increase from 523 to $543 \mathrm{~K}$. The $\mathrm{Ag}$ content in alloys affects $\mathrm{F}_{\max }$ at $523 \mathrm{~K}$ significantly. However, at higher temperature, the results displayed no effect of $\mathrm{Ag}$ content in $\mathrm{F}_{\max }$ as there was almost no difference in $F_{\max }$ at 543 and $563 \mathrm{~K}$. At $523 \mathrm{~K}$, increasing Ag content to 0.5 mass \% lead to increase in $\mathrm{F}_{\max }$ from 2.84 to $4.76 \mathrm{mN}$. The improved $\mathrm{F}_{\max }$ of these alloys can be attributed to the addition of silver in the solder composition. All solder alloy used in this study, generally, showed a decrease in $t_{1}$ and increase in $\mathrm{F}_{\max }$ as $\mathrm{Ag}$ content in alloy is increased.

In order to study the effect of fluxes, wetting balance test was also conducted with RMA flux. The results obtained with the RMA flux, shown in Fig. 6, were focused at $523 \mathrm{~K}$ to reduce temperature effect. Different fluxes showed different effects on wettability. Lower $\mathrm{t}_{1}$ and higher $\mathrm{F}_{\max }$ indicates a 


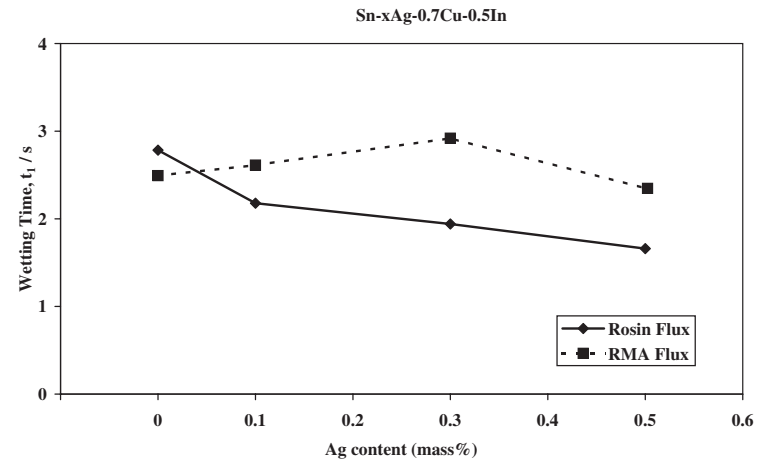

Fig. 6 Effect of fluxes on wetting time of lead-free solders at $250^{\circ} \mathrm{C}$.

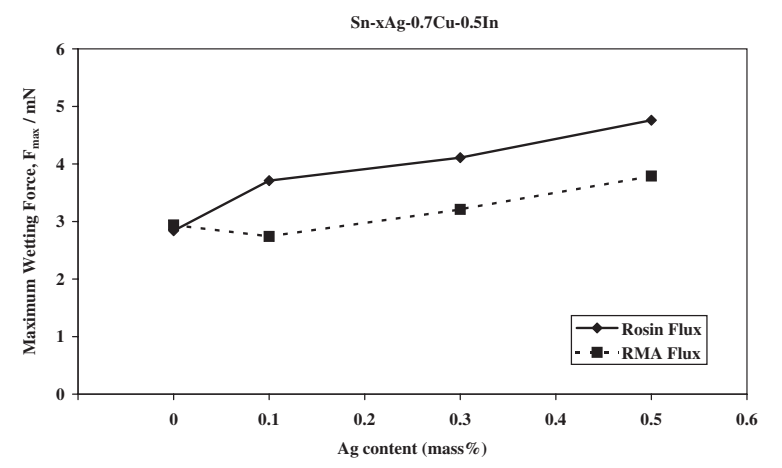

Fig. 7 Effect of fluxes on maximum wetting force of lead-free solders at $250^{\circ} \mathrm{C}$.

better wettability of a solder alloy. From all figures, the Rosin flux resulted in better wettability on all alloy. However, as it is indicated in Fig. 6, Sn-0.7Cu-0.5In (without $\mathrm{Ag}$ content) solder alloy with RMA flux showed $t_{1}$ is slightly lower than with Rosin flux. It is shown also that solder alloy with RMA flux, as increasing $\mathrm{Ag}$ content to 0.3 mass $\%$ resulted increasing in $\mathrm{t}_{1}$. In Fig. 7, the type of fluxes used on Sn0.7Ag-0.5In (without Ag content) solder alloy has less effect on $\mathrm{F}_{\max }$. However, the type of flux used displayed significant result when Ag adds in solder alloy.

From the results, generally, applying Rosin flux on the $\mathrm{Cu}$ substrate displayed better wettability, in this study are $t_{1}$ and $\mathrm{F}_{\max }$, compare with RMA flux. The alcohol as vehicle in rosin flux tends to evaporate at lower temperature than vehicle used in RMA flux. ${ }^{13)}$ As a consequence, the alcohol evaporates more gradually as temperature is raised. This property helps the reaction kinetic start early when the alcohol rapidly evaporates upon contact with the molten solders. Conversely, RMA flux requires higher preheat temperatures and longer times to maximize its volatilization. As a result, longer wetting time is obtained during wetting balance test.

\subsection{Contact angle measurement}

The result of contact angle measurement is shown in Fig. 8 displayed the effect of $\mathrm{Ag}$ content on contact angle at $523 \mathrm{~K}$. It is shown that addition of $\mathrm{Ag}$ in alloy affects the contact angle. At $523 \mathrm{~K}$, increasing Ag content to 0.1 mass $\%$ increase contact angle sharply from $31.18^{\circ}$ to $34.88^{\circ}$. Further increasing $\mathrm{Ag}$ content increase up to $0.5 \mathrm{mass} \%$ lead to

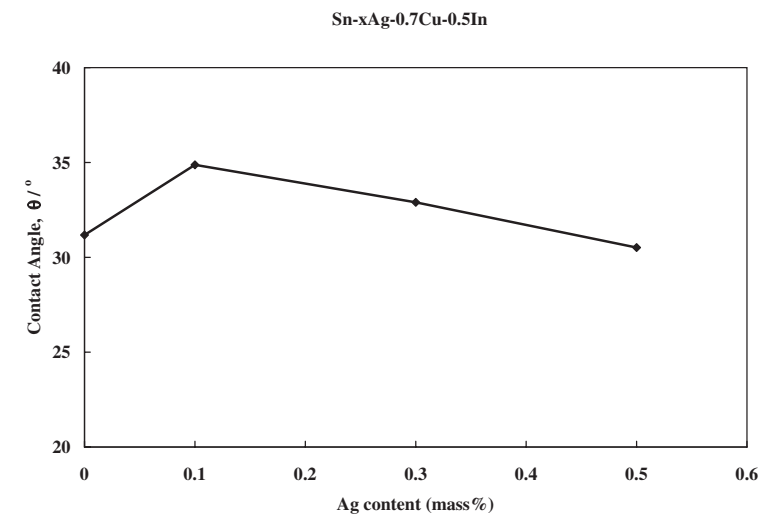

Fig. 8 Contact angle of lead-free solders at $250^{\circ} \mathrm{C}$ with Rosin flux.

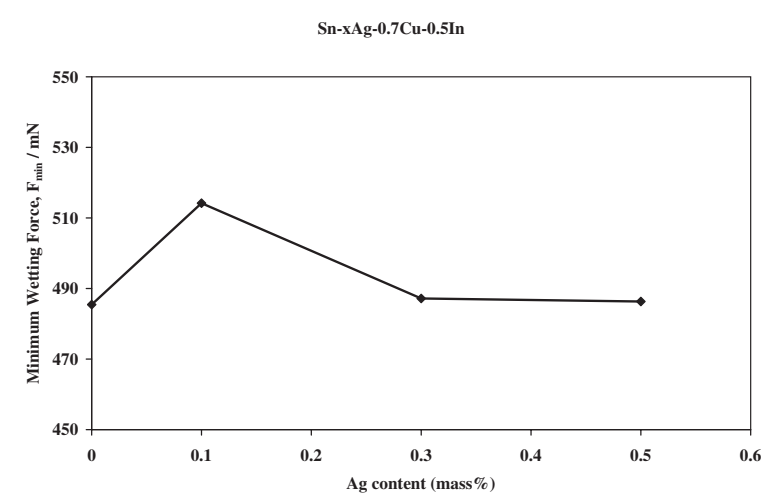

Fig. 9 Minimum wetting force of Sn- $x \mathrm{Ag}-0.7 \mathrm{Cu}-0.5 \mathrm{In}$ solders at $250^{\circ} \mathrm{C}$ with Rosin flux.

decrease contact angle to $30.52^{\circ}$. It is shown that $\mathrm{Sn}-0.7 \mathrm{Cu}-$ $0.5 \mathrm{In}$ and $\mathrm{Sn}-0.5 \mathrm{Ag}-0.7 \mathrm{Cu}-0.5 \mathrm{In}$ have similar result in contact angle at $523 \mathrm{~K}$. Minimum wetting force from wetting balance curve (Fig. 1) of the solders was analyzed to explain this fact. The minimum wetting force means the maximum counteraction force of the molten solder when the specimen depressed the molten solder surface before it immerse or wetting phenomena happened. Surface tension of molten solder alloys plays major role forming wetting balance curve from when the specimen touch the surface of molten solder until reach the minimum wetting force. Therefore, the minimum wetting force can also describe qualitatively the surface tension of solder alloy. However, the exact value of the surface tension need further experiment to examine.

In Fig. 8, the solder with 0.1 mass $\%$ Ag displayed the highest contact angle. It can be explained by referring the value of minimum wetting force $\left(\mathrm{F}_{\min }\right)$ at $523 \mathrm{~K}$, as it is shown in Fig. 9. From Fig. 9, the solder with 0.1 mass\% Ag also displayed the highest $\mathrm{F}_{\min }$. It indicates that this solder has highest surface tension among all solders used in this study. It is known that surface tension of solder can affect directly to contact angle, where increasing surface tension can increase the contact angle. ${ }^{14)}$ It can be concluded that high contact angle of 0.1 mass $\%$ Ag content solder was affected by high surface tension of the solder.

Increasing $\mathrm{Ag}$ content to 0.5 mass $\%$ resulted similar $\mathrm{F}_{\text {min }}$ with no Ag content alloy (Fig. 9). However, from previous result of $F_{\max }$ (Fig. 5), Sn-0.5Ag-0.7Cu-0.5In displayed 


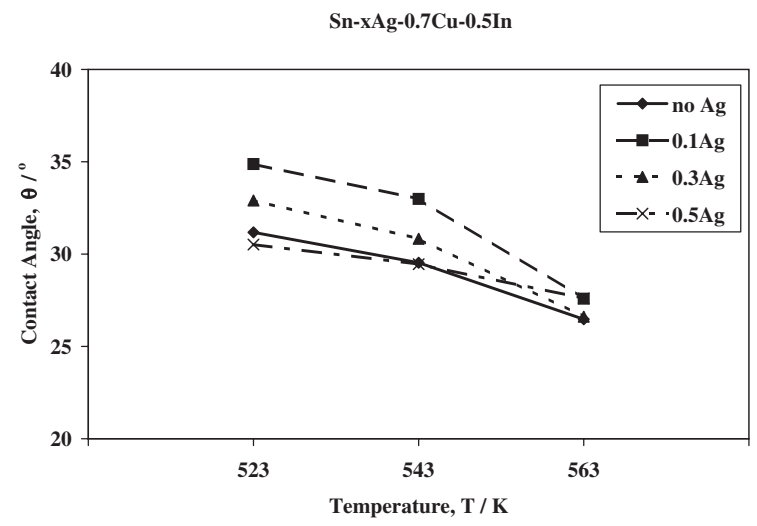

Fig. 10 Contact angle of lead free solders with Rosin flux.

significantly higher $\mathrm{F}_{\max }$ than $\mathrm{Sn}-0.7 \mathrm{Cu}-0.5 \mathrm{In}$ at $523 \mathrm{~K}$. This fact can be explained by eq. (1). According to eq. (1), temperature variation affects the surface tension, the contact angle, and density of solder, which in turn affect the wetting force. If the contact angles and surface tension are same, the only variable that can affect the wetting force are density of the solder. From this argument, in this study, Ag content in alloy affect the density of molten solder which 0.5 mass $\% \mathrm{Ag}$ content resulted significant difference of density showed by significant difference in $F_{\max }$ but similar result in contact angle and surface tension.

The measurement of contact angle was also performed at three temperatures with Rosin flux, as it is shown in Fig. 10. The results showed decreasing contact angle with increasing temperature for all alloys. Sn-0.5Ag-0.7 Cu-0.5In showed similar result in contact angle with $\mathrm{Sn}-0.7 \mathrm{Cu}-0.5 \mathrm{In}$ at all temperature. At $563 \mathrm{~K}$, all alloy displayed less difference in contact angle.

\section{Conclusion}

Small addition of $\mathrm{Ag}$ and temperature affect the wettability of solders. Higher Ag content showed better wettability. All solders used in this study displayed decreasing of $t_{1}$ and increasing of $F_{\max }$ when the temperature increases. The rosin flux gives better wettability, in this study is indicated by $t_{1}$ and $F_{\max }$, compare with RMA flux. Faster volatilization of rosin flux leads to enhancement of wettability. Contact angle of solder showed dependence on temperature where increasing temperature lead to decreasing of contact angle. Ag content in solder affects the contact angle. Addition 0.1 mass\% Ag increased contact angle; however further increasing $\mathrm{Ag}$ content in solder displayed decreasing of contact angle. Solder alloy with no Ag content and 0.5 mass $\%$ Ag content displayed similar contact angle and qualitatively similar surface tension. However, $\mathrm{F}_{\max }$ of those alloys were different. From static equilibrium equations, it indicated difference of density of solder alloys.

\section{Acknowledgement}

The work was supported by Japan International Cooperation Agency (JICA) under AUN/SEED-Net (ASEAN University Network/Southeast Asia Engineering Education Development Network) program.

\section{REFERENCES}

1) H. Wang, F. W. F. Gao, X. Ma and Y. Qian: J. Alloy. Compd. 433 (2007) 302-305.

2) L. N. Brush and R. N. Gruge: Mater. Sci. Eng. A 238 (1997) 176-171.

3) Y.-fu Yan, J.-hong Zhu, F.-xiao Chen, J.-guang He and D.-xin Yang: T. Nonferr. Metal. Soc. 16 (2006) 1116-1120.

4) H. S.-Hwan, K. K.-Soo and K. Suganuma: Mater. Trans. 42 (2001) 739-744.

5) Metal Handbook: Welding, brazing, and Soldering, 9th ed., 6 (American Society for Metal, Ohio, 1983).

6) M. Abtew and G. Selvaduray: Mater. Sci. Eng. A Rev. J. 27 (2000) 95-141.

7) S. Nurmi, J. Sundelin, E. Ristolainen and T. Lepisto: Microelectron. Reliab. 44 (2004) 485-494.

8) Z. Mei and J. W. Morris: J. Electron. Mater. 21 (1992) 401-407.

9) Z. Mei and J. W. Morris: J. Electron. Mater. 21 (1992) 599.

10) J. Y. Park, C. S. Kang and J. P. Jung: J. Electron. Mater. 28 (1999).

11) E. P. Lopez, P. T. Vianco and J. A. Rejent: J. Electron. Mater. 32 (2003).

12) C. M. L. Wu, C. M. T. Law, D. Q. Yu and L. Wang: J. Electron. Mater. 32 (2003).

13) Soldering Handbook, 3rd edition, (American Welding Society, Florida, 1999).

14) M. F. Arenas, M. He and V. L. Acoff: J. Electron. Mater. 35 (2006) $1530-1536$. 